\title{
Adenylate Cyclase Responsiveness to Hormones in Various Portions of the Human Nephron
}

\author{
Danielle Chabardès, Michèle Gagnan-Brunette, Martine Imbert-Teboul, \\ Olga Gontcharevskaia, Madeleine Montégut, André Clique, and \\ François Morel, Laboratoire de Physiologie Cellulaire, College de France, \\ 75231 Paris Cedex 05
}

A B S T RAC T The action sites for parathyroid hormone (PTH), salmon calcitonin (SCT), and argininevasopressin (AVP) were investigated along the human nephron by measuring adenylate cyclase activity, using a single tubule in vitro microassay. Well-localized segments of tubule were isolated by microdissection from five human kidneys unsuitable for transplantation.

PTH $(10 \mathrm{IU} / \mathrm{ml})$ increased adenylate cyclase activity in the convoluted and the straight proximal tubule, in the medullary and cortical portions of the thick ascending limb, and in the early portion of the distal convoluted tubule (corresponding stimulated:basal activity ratios were $64,19,10,18$, and 22 , respectively).

SCT $(10 \mathrm{ng} / \mathrm{ml})$ increased adenylate cyclase activity in the medullary and cortical portions of the thick ascending limb, in the early portion of the distal convoluted tubule, and, to a lesser extent, in the cortical and the medullary collecting tubule (activity ratios were $7,14,15,3$, and 3 , respectively).

AVP $(1 \mu \mathrm{M})$ stimulated adenylate cyclase activity in the terminal nephron segments only, i.e., the late portion of the distal convoluted tubule, the cortical and medullary portions of the collecting tubule (activity ratios 81,51 , and 97 , respectively).

As measured in one experiment, nearly one-half maximal responses were obtained with $0.1 \mathrm{IU} / \mathrm{ml} \mathrm{PTH}$ or $0.3 \mathrm{ng} / \mathrm{ml}$ SCT in thick ascending limbs and with $1 \mathrm{nM}$ AVP in collecting tubules, suggesting that enzyme sensitivity to hormones was well preserved under the conditions used in this study.

A preliminary report of this research was presented at the VIIth International Congress of Nephrology, Montreal, June 1978.

Dr. Gagnan-Brunette's current address is Hospital Maisonneuve-Rosemont, Montreal, Canada. Dr. Gontcharevskaia's current address is Intitut Setchenov, Leningrad, U.S.S.R.

Received for publication 9 July 1979 and in revised form 28 September 1979.

\section{INTRODUCTION}

Little is yet known about the sites and mechanisms of hormonal action along the nephron in the human kidney. Of the current physiological approaches used in animals, clearance studies have been widely applied to man. Unfortunately, however, they only permit measurement of overall effects, which cannot be localized on the scale of the nephron. Micropuncture techniques cannot be used in man for obvious reasons. In vitro microperfusion of isolated tubules has only been applied to human kidney in very few cases $(1,2)$. Thus, Abramow and Dratwa (1) observed the response of a single fetal collecting tubule to vasopressin.

Specific biochemical approaches were also applied to studies using human kidneys. Vasopressin (3) and also glucagon and isoproterenol (4) were reported to stimulate adenylate cyclase contained in human kidney medulla, whereas parathyroid hormone $(5,6)$ and, to a lesser extent, glucagon, isoproterenol, and calcitonin (6) enhanced enzyme activity in the cortex. The exact sites of action of these hormones, however, could not be deduced from these studies, because they used whole tissue homogenates. To overcome this limitation, inherent in the cell heterogeneity of renal tissue, it is necessary to investigate the effects of hormones on adenylate cyclase activity by using samples containing only pure, homogeneous, and well-localized segments of the nephron. One possibility is to apply an adenylate cyclase microassay to samples containing a single piece of tubule, as they can be isolated by microdissection of collagenase-treated kidneys $(7,8)$. This method was used in the present study to investigate the action of parathyroid hormone, calcitonin, and vasopressin on the adenylate cyclase contained in most of the segments of the human nephron.

\section{METHODS}

Kidneys. Five adult, human kidneys were used in this study. They were kindly provided by France-Transplant 
(Hôpital Necker, Paris) after having been judged unsuitable for transplantation. According to the information we were given, all kidneys were perfused with Collins' solution via the renal artery $(500 \mathrm{ml}$ in about $4-5 \mathrm{~min})$, then immersed in ice-cold Collins' solution as for transplantation. The composition of the Collins' solution is: $\mathrm{NaHCO}_{3}$, $10 \mathrm{mM} ; \mathrm{KCl}, 15 \mathrm{mM} ; \mathrm{KH}_{2} \mathrm{PO}_{4}, 15 \mathrm{mM} ; \mathrm{K}_{2} \mathrm{HPO}_{4}, 42.5 \mathrm{mM}$; and glucose $150 \mathrm{mM}$. The kidneys were stored under these conditions until the experiments started. The origin and length of storage of the kidneys were as follows: kidney No. 1, from a 18-year-old male killed in a traffic accident, storage, about $24 \mathrm{~h}$; kidney No 2 , from a 16-year-old male also killed in a traffic accident, storage, about $36 \mathrm{~h}$; kidney No. 3, age and cause of death not indicated, storage, about $48 \mathrm{~h}$; kidney No. 4, from a 53-year-old male who died of a brain hemorrhage, storage, $48 \mathrm{~h}$; kidney No. 5, from a 48-year-old female, cause of death not indicated, storage about $12 \mathrm{~h}$.

Experimental procedure. At the time of the experiment, a polyethylene tube was inserted into a branch of the renal artery and collagenase solution (see Solutions), colored by lissamine green, was perfused for a few minutes at a low temperature. The perfused zone of the kidney, as judged by the presence of the dye, was excised and then cut with a razor blade into small tissue pyramids including both cortex and outer medulla. These kidney pieces were incubated at $35^{\circ} \mathrm{C}$ in gassed collagenase solution for $60-90 \mathrm{~min}$. They were then transferred for microdissection into Petri dishes filled with ice-cold microdissection solution (see Solutions). The required nephron segments were isolated by hand with fine steel needles under stereomicroscopic observation. Each isolated structure $(0.5-1.5 \mathrm{~mm}$ in length, depending on the segment) was sucked out and transferred with a small droplet of microdissection solution onto the hollow part of a concave bacteriological glass slide. The piece of tubule was then photographed for subsequent measurement of its length, the glass slide was tightly covered, and the sample was processed for adenylate cyclase activity measurement, as reported in detail $(7,8)$. Briefly, the droplet of solution was aspirated and replaced by $0.5 \mu$ l hypoosmotic solution (see Solutions) containing the hormones when necessary. After about $30 \mathrm{~min}$ preincubation at ice-cold temperature, permeabilization of the tubule was completed by briefly freezing the sample (by contact of the slide with dry ice). $2 \mu$ l of incubation solution (see Solutions) were then added to each sample, the mixture was stirred by the action of an air stream, the glass slide was again tightly covered; and the sample was incubated for 30 min at $30^{\circ} \mathrm{C}$ by immersion in a temperature-regulated water bath. The enzyme reaction was terminated by adding $150 \mu l$ arrest solution (see Solutions) to the sample. The mixture was collected, added to $1 \mathrm{ml}$ distilled water, and successively filtered through a Dowex (Dow Corning Corp., Midland, Mich.) and an alumin column according to Salomon et al. (9), to separate the ${ }^{32} \mathrm{P}$-labeled cyclic AMP (cAMP) ${ }^{1}$ formed from its $\alpha{ }^{32} \mathrm{P}$-ATP precursor and from the other ${ }^{32} \mathrm{P}$-nucleotides. The yield of ${ }^{32} \mathrm{P}$-cAMP recovered was measured in all samples by adding tracer amounts of ${ }^{3} \mathrm{H}$-cAMP to the arrest solution.

Calculations. The adenylate cyclase (AC) activity of each

${ }^{1}$ Abbreviations used in this paper: AC, adenylate cyclase; AVP, arginine-vasopressin; CAL, cortical portion of the thick ascending limb of the loop of Henle; cAMP, cyclic AMP; CCT, cortical collecting tubule; DCT, distal convoluted tubule; MAL, medullary portion of the thick ascending limb of the loop of Henle; MCT, medullary collecting tubule; PCT, convoluted portion of the proximal tubule; PR, straight portion of the proximal tubule; $\mathrm{PTH}$, parathyroid hormone; SCT, salmon calcitonin; $\mathrm{V}_{\max }$, maximum velocity. sample, i.e., the amount of ATP converted into cAMP during the incubation period, was obtained by dividing the ${ }^{32} \mathrm{P}$-cAMP radioactivity counted (after correction for the radioactivity of blank samples and for cAMP recovery) by the ${ }^{32} \mathrm{P}-\mathrm{ATP}$ specific radioactivity measured under the same conditions. Because the protein content per sample $(\sim 0.1-0.2 \mu \mathrm{g})$ was far too low to be measured, the length of the piece of tubule was used as the reference, and the results were expressed as femtomoles cAMP formed per millimeter of tubule per 30 min incubation time at $30^{\circ} \mathrm{C}$.

When possible, three to five replicate samples of the same nephron portion were measured per experiment under each condition tested (basal and hormone-stimulated AC activities). This allowed statistical independent $t$ test to be applied to each individual experiment. It was not possible, however, to analyze the effects of parathyroid hormone (PTH), salmon calcitonin (SCT), and arginine-vasopressin (AVP) on all nephron segments in each experiment, since only about 80-100 samples of tubule could be dissected and prepared per kidney. For those nephron segments that could not be obtained in a large enough number of samples per experiment, mean value calculations and statistical analysis were performed by pooling all the data obtained in the experimental series. In the tables, all mean values are given with the corresponding SEM and the number of samples.

Morphological controls. The photographs of the freshly microdissected tubules were not only used to measure the length of each sample, but also to calculate tubular outer diameters. For each picture, 8-12 measurements were made at different sites along the piece of tubule. The corresponding average value was assumed to be an accurate outer diameter value because no great changes in diameter were generally noted along the structure.

Finally, in experiments 4 and 5, some pieces of kidney tissue were also macerated in hydrochloric acid according to Oliver (10). It was possible to isolate by microdissection 17 complete, unbroken human nephrons from these pieces of kidney. The average full length of the distal segments used for AC measurement was calculated from these nephrons.

Solutions. The microdissection solution was a modified Hanks' solution (11) containing, in millimolars: $\mathrm{NaCl}, 137$; $\mathrm{KCl}, 5 ; \mathrm{MgSO}_{4}, 0.8 ; \mathrm{Na}_{2} \mathrm{HPO}_{4}, 0.33 ; \mathrm{KH}_{2} \mathrm{PO}_{4}, 0.44 ; \mathrm{MgCl}_{2}$, 1; Tris $\mathrm{HCl}, 10$; and $\mathrm{CaCl}_{2}, 0.25 ; \mathrm{pH}, 7.4$. The collagenase solution was similar to the microdissection solution except that it contained $1 \mathrm{mM} \mathrm{CaCl}$ and $0.1 \% \mathrm{wt} / \mathrm{vol}$ of both collagenase and bovine serum albumin. The hypoosmotic solution contained in millimolars: EDTA, $0.25 ; \mathrm{MgCl}_{2}, 1$; Tris $\mathrm{HCl}$, 8 ; and bovine serum albumin, $0.1 \%$; $\mathrm{pH}, 7.4$. When necessary, hormones were added to this solution at a concentration fivefold that required in the final incubate. The incubation solution had a composition calculated so as to obtain a final incubate $(2 \mu$ l incubation solution added to $0.5 \mu$ l hypoosmotic solution) with the following concentrations: $\alpha{ }^{32} \mathrm{P}-\mathrm{ATP}, 0.25-$ $0.3 \mathrm{mM}, \sim 1 \mu \mathrm{Ci} / \mathrm{sample}$; cAMP, $1 \mathrm{mM}$; EDTA, $0.25 \mathrm{mM}$; $\mathrm{MgCl}_{2}, 4.0 \mathrm{mM}$; phosphocreatine, $20 \mathrm{mM}$; creatine kinase, $1 \mathrm{mg} / \mathrm{ml}$; and Tris $\mathrm{HCl}, 100 \mathrm{mM} ; \mathrm{pH}$ 7.4. The arrest solution contained: ATP, $3.3 \mathrm{mM}$; cAMP, $5 \mathrm{mM}$, including tracer amounts of ${ }^{3} \mathrm{H}$-cAMP and Tris $\mathrm{HCl}, 50 \mathrm{mM}$; pH 7.6.

Hormones and radiochemicals. PTH: 1-34 synthetic fragment of bovine PTH (3850 IU/mg) was purchased from Beckman Instruments, Inc., Fullerton, Calif. Calcitonin: synthetic SCT was kindly provided by Sandoz Pharmaceutical Div., Hanover, N. J.; arginine-vasopressin: highly purified AVP, prepared according to Pruzik et al. (12) was generously donated by T. Barth (Czechoslovak Academy of Sciences, Institute of Organic Chemistry and Biochemistry, Praha). $\alpha^{-}{ }^{32} \mathrm{P}$-ATP $(10-20 \mathrm{Ci} / \mathrm{mmol}$, sp act) was purchased from New England Nuclear, Boston, Mass. and ${ }^{3} \mathrm{H}-\mathrm{cAMP}$, from 
Commissariat à l'Energie, Saclay, France. Collagenase was extracted from clostridium histolyticum (Type I; Sigma Chemical Co., St. Louis, Mo.). Other reagents were of grade A as specified (13).

\section{RESULTS}

Segments analyzed. AC sensitivity to PTH (10 $\mathrm{IU} / \mathrm{ml})$, SCT $(10 \mathrm{ng} / \mathrm{ml})$, and AVP $(1 \mu \mathrm{M})$ was investigated in the following segments of the human nephron: the convoluted (PCT) and straight (PR) portions of the proximal tubule. The medullary (MAL) and cortical (CAL) portions of the thick ascending limb of the loop of Henle. PR and MAL samples were dissected from the outer medulla of the kidney and were easily distinguished from each other and from the medullary collecting tubules according to diameter, appearance under stereomicroscopic observation, and their level of transition into a thin segment. CAL samples were dissected in the cortex and identified by their small outer diameter, their bright aspect, their radial orientation, and their contact with a glomerulus at the macula densa site. In the case of distal convoluted tubules (DCT), dissection along their entire length was never possible in collagenase-treated human kidneys, because of incomplete collagen hydrolysis, packed organization of the convolutions, and fragility of the tubules. However, we did obtain samples of the early DCT portion measuring up to about $1.5 \mathrm{~mm}$ starting from the macula densa. A few samples of the late DCT portion (up to 1 $\mathrm{mm}$ ) were also obtained by dissecting distal tubules from their branching with a collecting tubule (CCT). When possible, the hormone-sensitive AC contained in these DCT samples was compared to that of the adjacent segment of the same nephron (CAL or CCT) tested under the same experimental conditions. CCT were dissected in all experiments. They were identified by their typical, light appearance, by the occasional presence of branching, and by their radial position in the "medullary rays" of the cortex. Finally, a few medullary collecting tubules (MCT) were dissected out of the outer medulla. The following nephron portions were not investigated: the glomerulus, the thin segments of the loop of Henle, the middle DCT portion, and the papillary collecting tubule.

Table I indicates the average outer diameter of the different nephron segments tested for their hormonesensitive AC activity. The table also gives the average length for the distal nephron portions defined above, as measured on unbroken nephrons dissected from pieces of human kidney macerated in hydrochloric acid.

Proximal tubule. Table II indicates the effects obtained with PTH and SCT on the PCT and the PR from kidneys 2 and 3. Compared to basal activity, PTH stimulated AC 40- to 50-fold in PCT, and 12- to 20-fold in PR. Two PCT and two PR samples were also measured in experiment 1 in the presence of $\mathrm{PTH}, 10 \mathrm{IU} / \mathrm{ml}$
TABLE I

Tubular Length and Diameter of Human Nephron Segments

\begin{tabular}{lcccr}
\hline \multicolumn{1}{c}{ Segment } & Length & $(n)$ & $\begin{array}{c}\text { Outer } \\
\text { diameter }\end{array}$ & $(n)$ \\
\hline & $m m \pm$ SE.M & & $\mu m \pm$ SE.M & \\
PCT & - & & $53.6 \pm 0.76$ & $(55)$ \\
PR & - & & $45.8 \pm 0.56$ & $(56)$ \\
MAL & $3.3 \pm 0.17$ & $(17)$ & $30.0 \pm 0.56$ & $(62)$ \\
CAL & $4.6 \pm 0.18$ & $(17)$ & $31.6 \pm 0.02$ & $(109)$ \\
MAL + CAL & $(7.9 \pm 0.17$ & $(17))$ & - & \\
Early DCT & $2.3 \pm 0.12$ & $(17)$ & $47.0 \pm 0.82$ & $(45)$ \\
Middle DCT & $1.7 \pm 0.10$ & $(17)$ & - & \\
Late DCT & $0.8 \pm 0.06$ & $(17)$ & $38.0 \pm 0.70$ & $(26)$ \\
Whole DCT & $(4.9 \pm 0.24$ & $(17))$ & - & \\
CCT & - & & $46.8 \pm 0.69$ & $(48)$ \\
MCT & - & & $50.1 \pm 1.06$ & $(19)$ \\
\end{tabular}

Tubular lengths indicated in this table are the mean values of the entire length of the corresponding segments measured on 17 unbroken microdissected nephrons from pieces of kidneys 4 and 5, macerated in hydrochloric acid. Tubular diameters correspond to mean values measured from the photographs of tubule samples used for AC activity measurement (kidneys 1-5). In brackets, the number of tubules used for such determinations.

(PCT, 1,038 $\pm 205 \mathrm{SE}$ and PR $371 \pm 170 \mathrm{fmol} / \mathrm{mm} \cdot 30$ min). It is therefore clear that human PCT and PR contain AC sensitive to PTH. Moreover, higher responses to PTH were obtained in PCT than in PR in these three human kidneys, as observed earlier in rabbit (14) and mouse (15) kidneys.

SCT induced no significant increase in AC activity compared to basal activity in these experiments, except in the PR samples of experiment 3, where the 31.9 mean value was statistically different $(P<0.05)$ from the corresponding control value. However, this SCT

\section{TABLE II}

AC Activities Measured in the PCT and PR in the Absence (Basal) or the Presence in the Incubate of either PTH $(10 \mathrm{IU} / \mathrm{ml})$ or SCT $(10 \mathrm{ng} / \mathrm{ml})$

\begin{tabular}{|c|c|c|c|}
\hline \multirow[b]{2}{*}{ Kidney } & \multirow{2}{*}{$\begin{array}{c}\text { Condi- } \\
\text { tion }\end{array}$} & \multicolumn{2}{|c|}{ AC activity ( \pm SEMI) } \\
\hline & & PCT & PR \\
\hline & & \multicolumn{2}{|c|}{$\mathrm{fmol} / \mathrm{mm} \cdot 30 \mathrm{~min}$} \\
\hline \multirow[t]{3}{*}{2} & Basal & $7.4 \pm 2.1$ & $10.7 \pm 1.6$ \\
\hline & SCT & $7.7 \pm 3.1$ & $11.8 \pm 1.8$ \\
\hline & РTH & $278.3 \pm 27.1(4)$ & $123.8 \pm 25.3(3)$ \\
\hline \multirow[t]{3}{*}{3} & Basal & $6.4 \pm 2.8$ & $10.9 \pm 2.1$ \\
\hline & SCT & $8.6 \pm 1.0$ & $31.9 \pm 6.9$ \\
\hline & РTH & $330.1 \pm 65.3(5)$ & $193.3 \pm 13.1(5)$ \\
\hline
\end{tabular}

In brackets, the number of samples used. 
effect was of very limited magnitude compared to the action of PTH. In addition, when the data obtained in the different experiments were pooled, SCT produced no statistically significant effect on either PCT or PR AC activities.

In these experiments, AVP $(1 \mu \mathrm{M})$ had no effect on PCT (10.0 \pm 3.0 SE [6]; control, $6.9 \pm 1.6$ [8]) and induced a nonsignificant increase in PR $(34.8 \pm 12.4$ [6]; control $10.8 \pm 1.3$ [7], $\mathrm{P}>0.05$ ).

Thick ascending limb of the loop. The results obtained with PTH, SCT, and AVP on the MAL (three experiments) and the CAL (five experiments) of the thick limb are shown in Table III. AVP induced no stimulation of AC in either MAL or CAL in any experiment except but No. 3. In contrast, PTH and SCT increased the AC activity of both structures in each experiment. On an average, the stimulated over basal activity ratio was 13 (SCT) and 18 (PTH) in CAL, and 8 (SCT) and $\sim 10(\mathrm{PTH})$ in MAL. The effects were highly significant for each experiment $(<0.01)$, as well as for the average value $(\mathrm{P}<0.001)$. In both structures, the response induced by PTH was always definitely higher than that induced by SCT. Therefore, in human kidneys, the MAL and CAL contained AC of similar sensitivity to the three hormones tested, i.e., AC was responsive to PTH and SCT and unresponsive to AVP.

$D C T$. The results obtained with the same hormones on the samples of early and late DCT from three kidneys (experiments 2, 3, and 5) were pooled and are given in Table IV. The average lengths of the corresponding samples of tubule are also shown in this table.
The early DCT portion ( $1 \mathrm{~mm}$ long) exhibited high AC responsiveness to PTH (22-fold increase) and to SCT (15-fold increase). Absolute values per millimeter of tubule were clearly higher in early DCT than in MAL and CAL for the two hormones (compare Tables III and IV). Vasopressin produced no AC stimulation in early DCT.

In late DCT portions ( $\sim 0.5 \mathrm{~mm}$ long), AC exhibited much lower responsiveness to SCT and PTH than in early DCT portions. In contrast, late DCT was highly sensitive to AVP. Thus, the early and late portions of DCT contain AC of different responsiveness to the three hormones. The changing AC sensitivity pattern along the human DCT was not analyzed because, as indicated, samples of the middle DCT portion could not be microdissected in collagenase-treated human kidneys. Paired samples corresponding to successive portions of the same nephron were, nevertheless, analyzed in the presence of either PTH or AVP. The data are shown in Fig. 1. Clearly, early DCT samples responded to $\mathrm{PTH}$ more than the paired CAL samples (500-1000 instead of $150-300 \mathrm{fmol} / \mathrm{mm} \cdot 30 \mathrm{~min}$, respectively). PTH responses were of limited magnitude in late DCT samples and absent in the paired CCT samples. As regards the response to AVP, it was negligible in CAL and early DCT samples, high in late DCT samples, and even higher in the paired CCT samples.

CCT. The results obtained on CCT are given in Table V. SCT induced a small two- to three-fold AC stimulation, which was statistically significant in experiments $1,3(\mathrm{P}<0.025)$, and $5(\mathrm{P}<0.005)$, and for the mean value $(\mathrm{P}<0.001)$. With $\mathrm{PTH}$, a statistically

TABLE III

AC Activities Measured in the MAL and CAL in the Absence of Hormone (Basal) or the Presence of Either SCT (10 $\mathrm{ng} / \mathrm{ml})$, PTH (10 IU/ml), or AVP (1 $\mu \mathrm{M})$

\begin{tabular}{|c|c|c|c|c|}
\hline \multirow[b]{2}{*}{ Kidney } & \multirow[b]{2}{*}{ Basal } & \multicolumn{3}{|c|}{ AC activity $( \pm$ SEM) } \\
\hline & & SCT & PTH & AVP \\
\hline & & & $\mathrm{fmol} / \mathrm{mm} \cdot 30 \mathrm{~min}$ & \\
\hline \multicolumn{5}{|l|}{ MAL } \\
\hline 2 & $14.2 \pm 1.3(4)$ & $79.7 \pm 8.3$ & $116.5 \pm 15.3(4)$ & $17.6 \pm 1.8(6)$ \\
\hline 3 & $11.1 \pm 0.7(3)$ & 196.9 & $247.9 \pm 9.2$ & $22.5 \pm 0.9(3)$ \\
\hline 4 & $38.7 \pm 5.4(5)$ & $231.7 \pm 25.6(5)$ & $306.7 \pm 48.3(7)$ & $37.7 \pm 6.3(6)$ \\
\hline mean & $21.3 \pm 8.7(3)$ & $169.4 \pm 46$ & $223.7 \pm 56.2(3)$ & $25.9 \pm 6.1(3)$ \\
\hline \multicolumn{5}{|l|}{ CAL } \\
\hline 1 & $24.9 \pm 2.1(6)$ & $364.6 \pm 17.0(6)$ & $509.9 \pm 46.0(6)$ & $29.3 \pm 1.9(10)$ \\
\hline 2 & $15.0 \pm 2.5(4)$ & $229.5 \pm 17.1(4)$ & $289.6 \pm 13.2(5)$ & $16.9 \quad$ (2) \\
\hline 3 & $12.7 \pm 1.5(4)$ & $224.1 \pm 30.0(4)$ & $242.3 \pm 43.0(4)$ & $23.7 \pm 2.1(4)$ \\
\hline 4 & $22.1 \pm 6.6(5)$ & $164.8 \pm 32.8(6)$ & $317.9 \pm 45.3(6)$ & $30.9 \pm 3.2(4)$ \\
\hline 5 & $10.5 \pm 4.0(4)$ & $138.9 \pm 23.6(4)$ & $206.5 \pm 16.4(5)$ & $8.4 \pm 0.7(4)$ \\
\hline mean & $17.0 \pm 2.8(5)$ & $224.4 \pm 39.1(5)$ & $313.2 \pm 52.8(5)$ & $21.8 \pm 4.2(5)$ \\
\hline
\end{tabular}

In brackets, the number of samples used. Mean, the average value $( \pm S E M)$ for the different experiments. 
TABLE IV

AC Activity and Average Tubular Length Measured in the Early and the Late Portions of DCT Dissected from Kidneys 2, 3, and 5

\begin{tabular}{|c|c|c|c|c|c|c|}
\hline \multirow{2}{*}{$\begin{array}{l}\text { Condi- } \\
\text { tion }\end{array}$} & \multicolumn{2}{|c|}{ Early DCT } & \multirow[b]{2}{*}{ (n) } & \multicolumn{2}{|c|}{ Late DCT } & \multirow[b]{2}{*}{$(n)$} \\
\hline & AC activity & Length & & AC activity & Length & \\
\hline & \multicolumn{3}{|l|}{$\mathrm{fmol} / \mathrm{mm} \cdot 30 \mathrm{~min}$} & \multicolumn{2}{|l|}{$\mathrm{fmol} / \mathrm{mm} \cdot 30 \mathrm{~min}$} & \\
\hline Basal & $37.2 \pm 3.5$ & $0.62 \pm 0.08$ & (9) & $6.0 \pm 2$ & $0.44 \pm 0.09$ & (3) \\
\hline SCT & $566.2 \pm 38.9$ & $1.20 \pm 0.08$ & (9) & 35.6 & 0.51 & (2) \\
\hline РTH & $812.6 \pm 74.0$ & $1.02 \pm 0.10$ & (13) & $107.5 \pm 24.2$ & $0.56 \pm 0.07$ & (11) \\
\hline AVP & $44.0 \pm 6.2$ & $1.05 \pm 0.11$ & $(7)$ & $493.6 \pm 22.5$ & $0.51 \pm 0.08$ & (6) \\
\hline
\end{tabular}

All data were pooled. $(n)$, number of samples used. SCT, $10 \mathrm{ng} / \mathrm{ml}$; PTH, $10 \mathrm{IU} / \mathrm{ml}$; AVP $1 \mu \mathrm{M}$ in the incubate.

significant increase in $\mathrm{AC}$ activity was obtained in experiment 4 only $(P<0.01)$. In contrast, huge AC activities were always obtained with AVP. On an average, AVP stimulated 50-fold the enzyme contained in CCT.

MCT. Results similar to those for CCT were observed in the medullary portion of the collecting tubule as tested in experiments 3 and 4: basal, 12.1 $\pm 2.1 \mathrm{SE}(6)$; SCT, $27.8 \pm 2.5$ (3) $(\mathrm{P}<0.01)$; and AVP, $1035.5 \pm 60.6(6)$. PTH action was not tested.

Fig. 2 summarizes the results obtained in this study as regards the effects of PTH, SCT, and AVP on the $A C$ activity contained in the different nephron segments. Each column gives the average increase in AC activity obtained by pooling all the samples measured under the corresponding experimental condition.

Hormonal response sensitivity. All data given in Tables II-VI and in Fig. 2 probably correspond to maximal effects because the hormonal concentrations used in this study were about ten times higher than those observed to induce maximal AC stimulations in

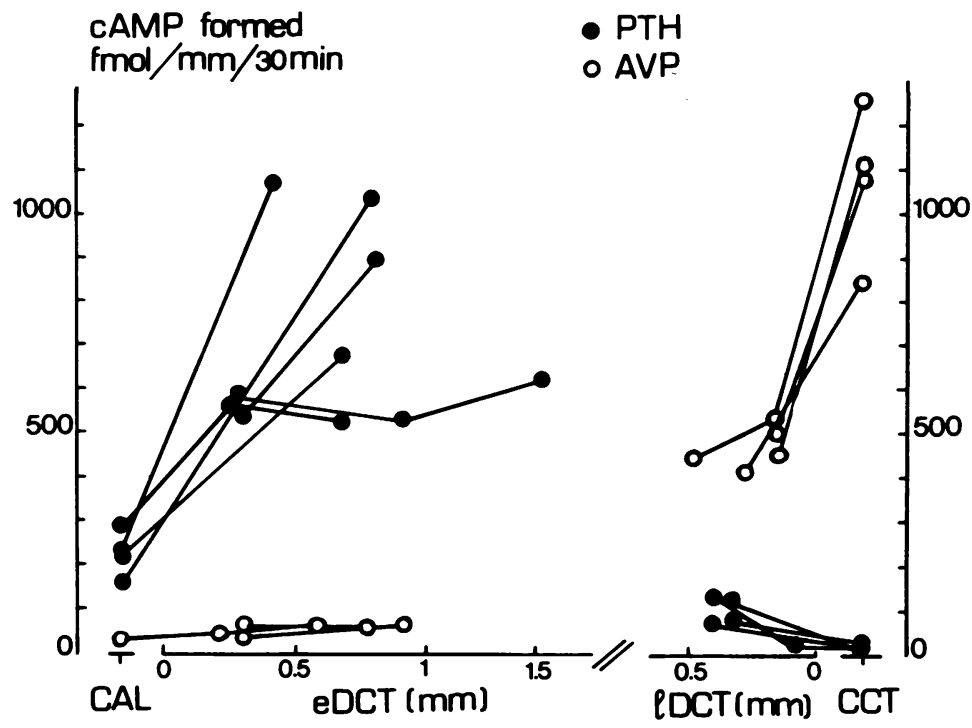

Figure 1 Changes in hormone-dependent AC activity along the distal segments. The lines on the figure join either CAL and early DCT (eDCT) samples or CCT and late DCT (IDCT) samples microdissected from the same nephron. Early DCT samples were separated from CAL samples by cutting the tubule at the macula densa. Late DCT samples were separated from CCT samples by cutting the tubule at the first branching site. In some cases, early or late DCT were further subdivided into two samples. In abscissa, left hand scale, the distance (in millimeters) from the macula densa site to the half-length point of early DCT samples, or, right hand scale, the distance from the half-length point of late DCT samples to the first branching site. In ordinate: AC activities measured in the presence of either PTH $(10 \mathrm{IU} / \mathrm{ml}, 0)$ or AVP $(1 \mu \mathrm{M}, \mathrm{O})$. Note the striking difference in hormonal sensitivity exhibited by the two end portions of the distal convoluted tubule. 
TABLE V

AC Activities Measured in the CCT

\begin{tabular}{|c|c|c|c|c|}
\hline \multirow[b]{2}{*}{ Kidney } & \multicolumn{4}{|c|}{ AC activity ( \pm SEM) } \\
\hline & Basal & SCT & PTH & AVP \\
\hline & \multicolumn{4}{|c|}{$\mathrm{fmol} / \mathrm{mm} \cdot 30 \mathrm{~min}$} \\
\hline 1 & $29.8 \pm 5.6(3)$ & $63.6 \pm 18.0(4)$ & - & $1,210.8 \pm 157.9(4)$ \\
\hline 2 & $28.2 \pm 2.7(4)$ & $56.4 \pm 14.2(3)$ & $39.2 \pm 5.6(5)$ & $676.8 \pm 59.3$ \\
\hline 3 & $8.0 \pm 1.1(4)$ & $28.8 \pm 8.6$ & $16.7 \pm 2.6(9)$ & 988.0 \\
\hline 4 & $12.5 \pm 3.5(3)$ & - & $29.7 \pm 3.2(4)$ & $836.2 \pm 48.9$ \\
\hline 5 & $15.9 \pm 0.3(4)$ & $36.1 \pm 4.1$ & $24.8 \pm 8.8(5)$ & $1,044.9 \pm 113.8(7)$ \\
\hline mean & $18.9 \pm 4.3(5)$ & $46.2 \pm 8.2$ & $27.6 \pm 4.7(4)$ & $951.4 \pm 91.1$ \\
\hline
\end{tabular}

SCT, $10 \mathrm{ng} / \mathrm{ml}$; PTH, $10 \mathrm{IU} / \mathrm{ml}$; AVP, $1 \mu \mathrm{M}$ in the incubate. In brackets, the number of samples used.

isolated rabbit tubules $(14,16,17)$. In one experiment (No. 5) the sensitivity of the cyclase to hormones was estimated for vasopressin in CCT, and for calcitonin and PTH in CAL by measuring the response obtained in the presence of much lower hormonal concentrations. The concentrations selected for this experiment were those observed to induce about one-half maximal stimulations in rabbit tubules. The results are given in Table VI, which shows that in CAL, $0.1 \mathrm{IU} / \mathrm{ml} \mathrm{PTH}$ induced exactly one-half the response obtained with
$10 \mathrm{IU} / \mathrm{ml}$. The CAL response to $0.3 \mathrm{ng} / \mathrm{ml}$ SCT was $36 \%$ of that obtained with $10 \mathrm{ng} / \mathrm{ml}$. Finally, in CCT samples, the response to $1 \mathrm{nM}$ AVP amounted to $45 \%$ of that induced by $1 \mu \mathrm{M}$ AVP. Thus, in these human segments, AC sensitivity to AVP, PTH, and SCT was roughly similar to that reported for the rabbit.

\section{DISCUSSION}

The results shown in Tables II-VI demonstrate that high hormone-dependent $\mathrm{AC}$ activity can be measured

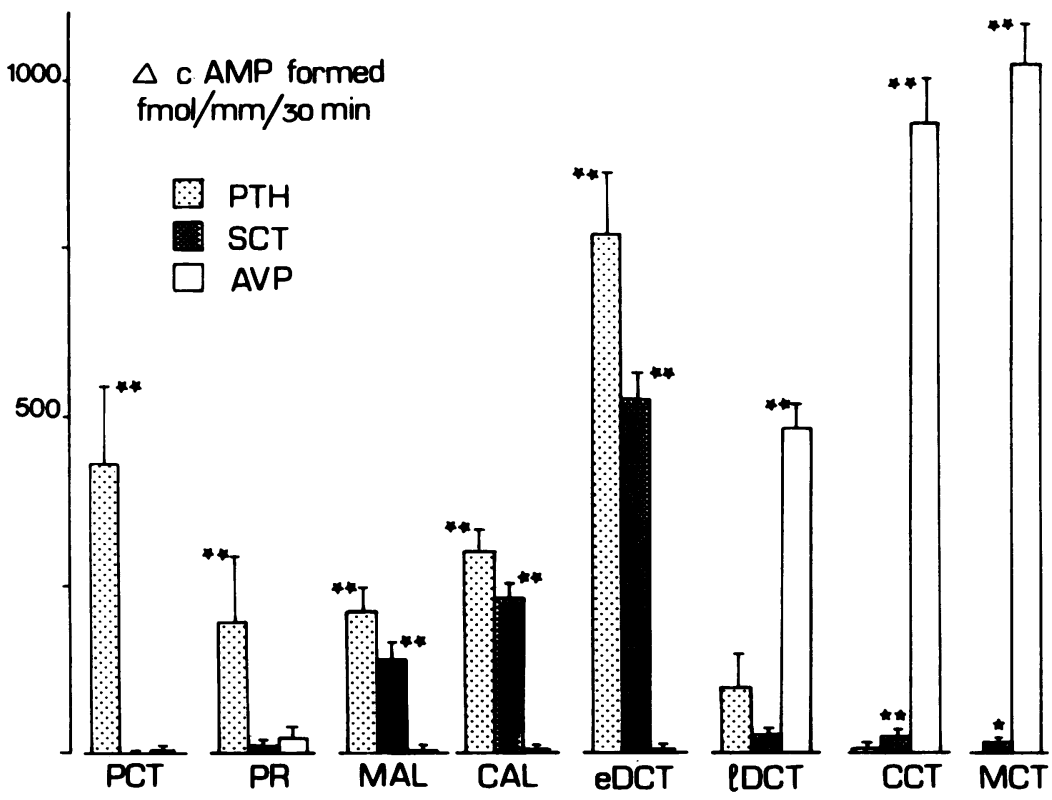

FIGURE 2 Distribution of hormone-sensitive AC activity along the human nephron. AC activities are given as increases in cAMP generation (stimulated minus basal). AC stimulation was induced by PTH $(10 \mathrm{IU} / \mathrm{ml})$, SCT $(10 \mathrm{ng} / \mathrm{ml})$, or AVP $(1 \mu \mathrm{M})$. Each bar is the mean value calculated by pooling all data obtained in the different experiments. Standard error of the mean is indicated for each experimental condition. eDCT, early DCT; IDCT, late DCT. Asterisks indicate levels of statistical significance compared to the corresponding basal mean value; $*=p<0.05 ; * *=p$ $<0.005$. Note that in late DCT AC stimulation by PTH was not statistically significant because of the large scatter of the data (see Table IV). 
TABLE VI

AC Sensitivity

\begin{tabular}{|c|c|c|}
\hline Condition & AC activity & Level of significance \\
\hline \multicolumn{3}{|c|}{$\mathrm{fmol} / \mathrm{mm} \cdot 30 \mathrm{~min}$} \\
\hline CAL & & \\
\hline Basal & $10.5 \pm 4.0$ & \\
\hline PTH, $0.1 \mathrm{IU} / \mathrm{ml}$ & $107.6 \pm 12.1$ & $\begin{array}{c}P<0.001 \text { vs } \\
\text { basal }\end{array}$ \\
\hline PTH, $10 \mathrm{IU} / \mathrm{ml}$ & $206.5 \pm 16.4$ & $\begin{array}{l}P<0.001 \text { vs. } \\
\text { PTH } 0.1 \mathrm{IU} / \mathrm{ml}\end{array}$ \\
\hline $\mathrm{SCT}, 0.3 \mathrm{ng} / \mathrm{ml}$ & $57.2 \pm 6.8$ & $\begin{array}{l}P<0.001 \text { vs. } \\
\text { basal }\end{array}$ \\
\hline $\mathrm{SCT}, 10 \mathrm{ng} / \mathrm{ml}$ & $138.9 \pm 23.6$ & $\begin{array}{c}P<0.01 \text { vs. SCT } \\
0.3 \mathrm{ng} / \mathrm{ml}\end{array}$ \\
\hline \multicolumn{3}{|l|}{ CCT } \\
\hline Basal & $15.9 \pm 0.3$ & \\
\hline AVP, $1 \mathrm{nM}$ & $468.8 \pm 62.6$ & $\begin{array}{c}P<0.001 \text { vs. } \\
\text { basal }\end{array}$ \\
\hline $\mathrm{AVP}, 1 \mu \mathrm{M}$ & $1,044.9 \pm 301.0(7)$ & $\begin{array}{l}P<0.01 \text { vs. } \\
\text { AVP } 1 \mathrm{nM}\end{array}$ \\
\hline
\end{tabular}

Kidney No. 5. AC activity ( \pm SEM) was measured in samples of the CAL in the presence of two concentrations of either PTH or SCT. Similarly, AC activity was measured in samples of the CCT in the presence of two concentrations of AVP. In brackets, the number of samples used.

in single tubules of human nephrons after up to $48 \mathrm{~h}$ of kidney storage at low temperature under the conditions used for organ transplantation. The scatter in AC activities observed from one experiment to another was not correlated with the duration of kidney storage. In experiment 5 for example ( $12 \mathrm{~h}$ storage), lower basal and PTH- or SCT-stimulated activities were measured in CAL than in the four other kidneys, whereas the effect of AVP in CCT was as high in this experiment as in the others. Similar variations in AC activities were also observed when freshly prepared homogenates or tubules $(18,19)$ from animal kidneys were used. The variable and generally lower $\mathrm{AC}$ response to $\mathrm{PTH}$ obtained in human as compared to mouse PCT (830 $\mathrm{fmol} / \mathrm{mm} \cdot 30 \mathrm{~min}$ ) (15) might be accounted for by the fact that $60-90 \mathrm{~min}$ of collagenase treatment at $35^{\circ} \mathrm{C}$ had to be applied to the human kidneys to make microdissection of the tubules possible. Nevertheless, the absolute activities measured in the other segments are in the same range of magnitude as those reported for rabbit with PTH $(14,20)$, calcitonin (16), and vasopressin $(17,20)$ under the same experimental condition. Furthermore, it is worth mentioning that the outer diameters measured here for isolated human kidney tubules (Table I) are not much larger than those measured in the corresponding segments of the rabbit nephron (unpublished results).

To compare the data given here with those reported in literature for human kidney homogenates, AC activities expressed per millimeter tubular length had to be converted into activities expressed per unit protein content. Tubular volumes per millimeter of length were calculated for each segment from outer diameter values (Table I). Protein content per millimeter of tubule was measured in different segments of rabbit kidney, microdissected under the same experimental conditions as those used here (8). From the corresponding outer diameters, it was calculated that the protein content corresponded to $\sim 13 \%$ of the tubular volume in these rabbit segments. The protein content per millimeter of tubular length was calculated for the human segments, assuming the same value. Table VII gives the corresponding figures, as well as the mean values for AC activities, expressed as picomoles cAMP formed per minute per milligram proteins.

In homogenates from normal human kidney tissue, basal AC activities ranging from 5 to $20 \mathrm{pmol} / \mathrm{min} \cdot \mathrm{mg}$ were reported for the cortex $(5,6)$ and from 7 to 12 $\mathrm{pmol} / \mathrm{min} \cdot \mathrm{mg}$ for the medulla, depending on the conditions used by the different authors $(3,4)$. Our basal values are lower, at least for the cortical segments.

Kim et al. (6) measured the AC response to PTH $(19 \mathrm{IU} / \mathrm{ml}), \operatorname{AVP}(1 \mu \mathrm{M})$, and calcitonin $(0.2 \mathrm{mg} / \mathrm{ml})$ in fresh homogenates of normal tissue cortex from a series of 10 patients. The PTH effect reported by these authors $(120 \mathrm{pmol} / \mathrm{min} \cdot \mathrm{mg}$ protein $)$ is greater than that reported by Brezner et al. (5) $\left(\mathrm{V}_{\max } 32 \mathrm{pmol} / \mathrm{min} \cdot \mathrm{mg}\right)$, but is comparable to the values obtained in this study. This agreement is not surprising because we observed that most of the tubular segments contained in the cor-

TABLE VII

Estimated AC Activity per. Milligram Protein Content

\begin{tabular}{|c|c|c|c|c|c|}
\hline \multirow[b]{2}{*}{ Segment } & \multirow{2}{*}{$\begin{array}{l}\text { Protein } \\
\text { content }\end{array}$} & \multirow[b]{2}{*}{ Basal } & \multicolumn{3}{|c|}{$\Delta$ cAMP } \\
\hline & & & PTH & SCT & AVP \\
\hline & $\mu g / m m$ & \multicolumn{4}{|c|}{$\mathrm{pmol} / \mathrm{min} \cdot \mathrm{mg}$ protein } \\
\hline PCT & 0.29 & 0.8 & 50 & 0 & 0 \\
\hline PR & 0.21 & 1.7 & 31 & 2 & 4 \\
\hline MAL & 0.09 & 8.8 & 80 & 54 & 1 \\
\hline CAL & 0.10 & 5.9 & 102 & 78 & 2 \\
\hline Early DCT & 0.22 & 5.6 & 118 & 80 & 1 \\
\hline Late DCT & 0.15 & 1.3 & 22 & 7 & 108 \\
\hline CCT & 0.22 & 2.8 & 1 & 4 & 142 \\
\hline MCT & 0.26 & 1.7 & - & 2 & 131 \\
\hline
\end{tabular}

In this table, average AC activities, calculated by pooling all data available for each experimental condition (Fig. 2) are expressed per minute incubation time and per milligram protein content. Responses to hormones are expressed as the average increase in AC activity (stimulated minus control AC mean values). Protein content per millimeter of tubular length was calculated for each nephron segment from outer diameter measurements (Table I), and by assuming that protein content represented $13 \%$ of tubular volume (wt/vol) (the volume of the lumen was disregarded in these calculations). 
tex, namely, PCT, PR, CAL, and DCT were PTH-sensitive. Only CCT was PTH-insensitive. As regards calcitonin and AVP, Kim et al. (6) observed very limited average effects in cortex homogenates, namely, in pmol/ min'mg: 17 (calcitonin) and 25 (AVP) compared to 14 (basal). When isolated tubules were used, these hormones induced huge responses, but only in very short nephron portions of the cortical structures, i.e., CAL and early DCT for calcitonin and late DCT and CCT for vasopressin. The larger cortical segment, PCT, was unresponsive. This probably explains the low responses to these hormones measured in homogenates. In the sensitive segments, however, SCT and AVP induced maximal responses of a magnitude comparable to that elicited by PTH on its own target portions. In homogenates of human kidney medulla, vasopressin stimulated AC about four- to fivefold $\left(\mathrm{V}_{\max }, 50-60 \mathrm{pmol} /\right.$ $\mathrm{min} \cdot \mathrm{mg}$ ) according to Mulvehill et al. (4) and Dousa (3). Compared to these data in the literature, our use of isolated tubules led to $V_{\max }$ values in the collecting tubules that were almost three times higher (Table VII). Here too, the difference might be accounted for by the presence of AVP-insensitive structures in homogenates of human medulla (PR and MAL).

Because of microdissection limitations, it was not possible to prepare enough samples of the same structure in human kidneys to establish complete dose-response curves. In experiment 5 (Table VI), however, the effects induced by low hormonal concentrations (roughly corresponding to the $K_{\mathrm{A}}$ values measured in rabbit segments) were compared to the maximal effects induced by high concentrations. From the results of Table VI, it may be estimated that in this human kidney, one-half maximal responses ( $K_{\mathrm{A}}$ values) corresponded to $0.1 \mathrm{IU} / \mathrm{ml}(6 \mathrm{nM})$ for PTH in CAL, to about $0.5 \mathrm{ng} / \mathrm{ml}$ $(0.15 \mathrm{nM})$ for SCT in CAL, and to $1-2 \mathrm{nM}$ for AVP in the CCT. These values are similar to those measured in the corresponding segments of the rabbit (14, $16,17)$. In homogenates from human kidney cortex, Drezner et al. (5) obtained one-half maximal stimulation with PTH concentrations of about $20 \mathrm{IU} / \mathrm{ml}$, and Monet et al. (21) with PTH concentrations (1-34 bovine fragment) of about $4 \mathrm{IU} / \mathrm{ml}$. In homogenates from human kidney medulla, Dousa (3) measured $20 \mathrm{nM}$ as the apparent $K_{\mathrm{A}}$ value for AC stimulation by AVP. All these values determined in homogenates are at least 10 times higher than those estimated here for the same hormone in isolated responsive segments.

In Man, as in other species, the sensitivity of AC to hormones is therefore better preserved in isolated tubules than in tissue homogenates. As discussed earlier (8) this might be a result of the absence of mechanical disruption of the cells when the single tubule micromethod is used.

The high AC sensitivity to low hormonal concentrations observed here, as well as the magnitude, specificity, and reproducibility of the stimulations obtained, suggest that the responsive segments (as revealed by this in vitro AC microassay) probably correspond to physiological target sites for the corresponding hormones in the living human kidney. As shown in Fig. 2 and Table VII, PTH stimulated AC activity in the proximal tubule (PCT and PR), the thick ascending limb (MAL and CAL), and the early portion of the DCT. Salmon calcitonin activated AC in the thick ascending limb (MAL and CAL), the early DCT, and, to a much lesser extent, in the CCT. Finally, AVP activated AC in the last nephron portions; the late DCT, the CCT, and the MCT. As already indicated, the middle portion of the DCT could not be tested in the human kidney. Because the entire DCT length is close to $5 \mathrm{~mm}$ in the human kidney (Table I) and because the tested portions were only about $1 \mathrm{~mm}$ for early DCT and $0.5 \mathrm{~mm}$ for late DCT, the larger DCT portion was not investigated here. In view of the marked differences noted for DCT between rabbit and mouse (22), it is difficult to speculate about possible AC sensitivity to the hormones of this middle portion by extrapolating to man the data so far obtained in other species of mammals. The high AC sensitivity towards PTH and SCT noted in human early DCT (Table IV) resembles that of the mouse (15) rather than the rabbit $(16,20)$ early DCT portion. Finally, human late DCT is likely to correspond to the late DCT portion of the mouse and superficial rabbit nephrons, judging from their common high responsiveness to vasopressin (22).

As regards the results obtained in the other segments of the human nephron, the MAL deserves mention. As shown in Table III, MAL AC in man was highly responsive to $\mathrm{PTH}$ and calcitonin, but not to vasopres$\sin$. This contrasts with the data reported for the three other species studied until now. In rat (18), mouse (22), and to a lesser extent, rabbit $(17,23)$ MAL always contained vasopressin-sensitive AC, whereas none of these species responded to PTH. The absence of vasopressin effect in human MAL as observed here might have resulted from some alteration of the receptor-coupling system caused by the conditions under which the kidneys were stored. However, such a specific loss in responsiveness to vasopressin remains an unlikely explanation in view of the following arguments. (a) The AC contained in collecting tubules responded to AVP under these storage conditions in man as much as in rabbit and rat under standard conditions. (b) Although insensitive to vasopressin, the enzyme contained in human MAL was highly responsive to PTH and SCT. (c) Finally, we performed a control experiment on a rat kidney that was perfused with Collins' solution and stored for $3 \mathrm{~d}$ in chilled Collins' solution before microdissection as for the human kidneys used here. All hormonal responses were found similar to those meas- 
ured in freshly dissected tubules. In particular, the response of the MAL to $1 \mu \mathrm{M}$ vasopressin was wellpreserved (basal, 18.2 $\pm 2.1 \mathrm{SE}$ [ $n=5$ ]; AVP-stimulated, $658 \pm 80[n=5] \mathrm{fmol} / \mathrm{min} \cdot 30 \mathrm{~min})$. It is therefore likely that AC is coupled to PTH and SCT receptors but not to vasopressin receptors in MAL of man, in contrast with MAL of rat, rabbit, and mouse.

The physiological significance of the species difference will be difficult to ascertain until we know better the nature of the final effects of PTH and calcitonin on the various responsive portions of the human nephron. Such species differences, however, indicate that the results obtained in laboratory animal species regarding the way hormones affect kidney functioning cannot be extrapolated to man without a great deal of caution.

In conclusion, this paper shows that hormone-sensitive AC can be measured in single tubules isolated from human kidneys stored for up to $2 \mathrm{~d}$ under transplantation conditions. As regards magnitude and sensitivity, the AC responses to PTH, SCT, and AVP are similar to those measured in freshly prepared rabbit kidney tubules. Species differences, however, are apparent in the distribution pattern of hormone action sites along the successive nephron portions.

In strains of rats (24) and mice (15) with inherited genetic diseases, specific changes in $\mathrm{AC}$ responses to either AVP or PTH, and SCT can be noted in some of the target nephron segments but not in others. Application of a single tubule AC microassay, such as the one described here, to the analysis of kidney tissue or biopsies from patients with various endocrine or metabolic diseases would no doubt produce similar information of use in pathophysiology and diagnosis.

\section{ACKNOWLEDGMENTS}

The authors are indebted to France-Transplant for kindly providing the required human kidneys.

This work was supported by a grant by Centre National de la Recherche Scientifique to the Laboratoire Associe 219 and by Institut National de la Santé et de la Recherche Medicale, Action Thématique Programmée No. 447676.

\section{REFERENCES}

1. Abramow, M., and M. Dratwa. 1974. Effect of vasopressin on the isolated human collecting duct. Nature (Lond.). 250: 492-493.

2. Jacobson, H. R., J. B. Gross, S. Kawamura, J. D. Waters, and J. P. Kokko. 1976. Electrophysiological study of isolated perfused human collecting ducts. Ion dependency of the transepithelial potential difference. J. Clin. Invest. 58: $1233-1239$.

3. Dousa, T. P. 1974. Interaction of lithium with vasopressinsensitive cyclic AMP system of human renal medulla. Endocrinology. 95: 1359-1366.

4. Mulvehill, J. B., Y. S. Hui, L. D. Barnes, P. J. Palumbo, and T. P. Dousa. 1976. Glucagon-sensitive adenylate cyclase in human renal medulla.J. Clin. Endocrinol. Metab. 42: $380-384$.
5. Drezner, M. K., and W. M. Burch, Jr. 1978. Altered activity of the nucleotide regulatory site in the parathyroid hormone-sensitive adenylate cyclase from the renal cortex of a patient with pseudohypoparathyroidism. J. Clin. Invest. 62: $1222-1227$.

6. Kim, J. K., P. P. Frohnert, Y. S. F. Hui, L. D. Barnes, G. M. Farrow, and T. P. Dousa. 1977. Enzymes of cyclic $3^{\prime}, 5^{\prime}$-nucleotide metabolism in human renal cortex and renal adenocarcinoma. Kidney Int. 12: 172-183.

7. Imbert, M., D. Chabardès, M. Montégut, A. Clique, and F. Morel. 1975. Adenylate cyclase activity along the rabbit nephron as measured in single isolated segments. Pfuegers Archiv. Eur. J. Physiol. 354: 213-228.

8. Morel, F., D. Chabardès, and M. Imbert-Teboul. 1978. Methodology for enzymatic studies of isolated tubular segments: adenylate cyclase. In Methods in Pharmacology. M. Martinez-Maldonado, editor. Plenum Publishing Corp., New York. Vol. 4 B. 297-323.

9. Salomon, Y., C. Londos, and M. Rodbell. 1974. A highly sensitive adenylate-cyclase assay. Anal. Biochem. 58: 541-548.

10. Oliver, J. 1968. Nephrons and Kidneys. Hoeber Medical Division, Harper \& Row, Publishers, Inc., New York.

11. Hanks, J. H., and R. E. Wallace. 1949. Relation of oxygen and temperature in the preservation of tissues by refrigeration. Proc. Soc. Exp. Biol. Med. 71: 196-199.

12. Pruzik, Z., E. Sedlákova, and T. Barth. 1972. Isolation of (Arg.8)-vasopressin from the neurophysin complex by free-flow continuous electrophoresis. Hoppe-Seyler's Z. Physiol. Chem. 353: 1837-1844.

13. Bockaert, J., C. Roy, and S. Jard. 1972. Oxytocin-sensitive adenylate cyclase in frog bladder epithelial cells. Role of calcium, nucleotides and other factors in hormonal stimulation. J. Biol. Chem. 247: 7073-7081.

14. Chadardès, D., M. Imbert, A. Clique, M. Montégut, and F. Morel. 1975. PTH sensitive adenyl cyclase activity in different segments of the rabbit nephron. Pfluegers Archiv. Eur. J. Physiol. 354: 229-239.

15. Brunette, M. G., D. Chabardès, M. Imbert-Teboul, A. Clique, M. Montégut, and F. Morel. 1979. Hormone-sensitive adenylate cyclase along the nephron of genetically hypophosphatemic mice. Kidney Int. 15: 357-369.

16. Chabardès, D., M. Imbert-Teboul, M. Montégut, A. Clique, and F. Morel. 1976. Distribution of calcitoninsensitive adenylate cyclase activity along the rabbit kidney tubule. Proc. Natl. Acad. Sci.U. S. A. 73: 3608-3612.

17. Imbert, M., D., Chabardès, M. Montégut, A. Clique, and F. Morel. 1975. Vasopressin dependent adenylate cyclase in single segments of rabbit kidney tubule. Pfluegers Archiv. Eur. J. Physiol. 357: 173-186.

18. Imbert-Teboul, M., D. Chabardès, M. Montégut, A. Clique, and F. Morel. 1978. Vasopressin dependent adenylate cyclase activities in the rat kidney medulla. Evidence for two separate sites of action. Endocrinology. 102: $1254-1261$

19. Rajerison, R., J. Marchetti, C. Roy, J. Bockaert, and S. Jard. 1974. The vasopressin sensitive adenylate cyclase of the rat kidney; effect of adrenalectomy and corticosteroids on hormonal receptor-enzyme coupling. J. Biol. Chem. 249: 6390-6400.

20. Morel, F., D. Chabardès, and M. Imbert. 1976. Functional segmentation of the rabbit distal tubule by microdermination of hormone-dependent adenylate cyclase activity. Kidney Int. 9: 264-277.

21. Monet, J. D., C. A. Bader, E. d'Herbigny, and J. L. FunckBrentano. 1978. In vitro relative biological activities of (1-34) N-terminal synthetic fragments of human parathy- 
roid hormone in the human renal cortical adenylate cyclase assay. FEBS (Fed. Eur. Biochem. Soc.) Lett. 96: 79-82.

22. Chabardès, D., M. Imbert-Teboul, M. Gagnan-Brunette, and F. Morel. 1978. Different hormonal target sites along the mouse and rabbit nephrons. In Current Problems in Clinical Biochemistry. W. G. Guder and U. Schmidt, editors. Hans Huber Publishers, Bern, Stuttgart, Vienna. Vol. 8. 447-454.

23. Imbert, M., D. Chabardès, M. Montégut, A. Clique, and
F. Morel. 1975. Présence d'une adényl-cyclase stimulée par la vasopessine dans la branche ascendante des anses des néphrons du rein de lapin. C. R. Acad. Sci. Ser. D. 280: 2129-2132.

24. Imbert-Teboul, M., D. Chabardès, M. Montégut, A. Clique, and F. Morel. 1978. Impaired response to vasopressin of adenylate cyclase of the thick ascending limb of Henle's loop in Brattleboro rats with diabetes insipidus. Renal Physiology. 1: 3-10. 